\title{
Nurses' Knowledge and Performance about Maintenance and prevention of Vascular Access Complications in Pediatric Hemodialysis Units
}

\author{
Maha I. Khalifa ${ }^{1}$,Omayma M. Okby ${ }^{2}$, Amal A. Fathala ${ }^{3}$ \\ Pediatric Nursing Department, Faculty of Nursing-Menoufia University ${ }^{1,2,3}$-Egypt
}

\begin{abstract}
The care of the child with chronic renal failure is complex and requires a multidisciplinary team. The success of hemodialysis treatment depends on nursing care provided for vascular access (temporary or permanent). For this reason, nurses should be able to develop their skills and knowledge in order to maintain and prevent of vascular access complications.
\end{abstract}

Aim: the study was carried out to assess nurses' Knowledge and Performance about the maintenance and prevention of vascular access complications in some pediatric hemodialysis units.

Settings: This study was conducted at pediatric hemodialysis units in Ministry of health hospitals and Menoufia university hospitals.

Design: A descriptive comparative design was selected.

Sample: A convenience sample of 100 staff nurses was obtained from the selected pediatric hemodialysis units in Menoufia governorate.

Tools:1).Knowledge assessment questionnaire to assess nurse's knowledge about hemodialysis vascular access 2).Observational check list to assess nurses' performance for the maintenance of vascular access and prevention of its complications.

Results: There were statistical significant differences between total nurses' knowledge in Ministry of health hospitals and Menoufia university hospitals about temporary vascular access, permanent vascular access, maintenance and follow-up of vascular access and general knowledge about vascular access. Statistical significant differences were found between total nurse's performance in Ministry of health hospitals and Menoufia university hospitals regarding temporary vascular access, permanent vascular access and the maintenance as well as follow-up of vascular access.

Conclusion: The knowledge of studied nurses about pediatric hemodialysis vascular access was inadequate. Moreover, nurses working at pediatric hemodialysis units in university hospital had better knowledge and practices related to the maintenance and follow-up of temporary vascular access and permanent vascular access.

Recommendations: In-service training education programs are needed to upgrade nurses' knowledge and practices in the maintenance and prevention of complications of temporary vascular access and permanent vascular access as well as maintenance and follow-up of vascular access.

Keywords: Hemodialysis, Vascular Access, Nurses' Knowledge, Nurses' Performance

\section{Introduction}

Chronic renal failure is a slow progressive loss of kidney function over a period of several year. Eventually the patient has permanent kidney failure. Chronic renal failure is much more common than people realize, and often becomes undetected and undiagnosed until the disease is well advanced and renal failure is failure occur [1].Currently younger children, including infants and toddlers with end-stage renal diseases (ESRD), who have failed peritoneal dialysis and who are not yet eligible for transplantation, need hemodialysis. Technical advances in equipment and vascular access have made chronic hemodialysis possible [2]. Most patients find hemodialysis more convenient than peritoneal dialysis. It is considerably less expensive as compared to peritoneal. The procedure is performed 2-3 days per week in the hospital. Each session lasts for 3-4 hours and patients are usually discharged thereafter. The overall aim of hemodialysis is to cleanse and filter the blood. It helps the body to get rid of harmful wastes, extra salt, and fluids. It also controls blood pressure and helps the body to keep the proper balance of electrolytes such as potassium, sodium, and chloride [3].

In pediatrics, hemodialysis is not offered to children less than 5 years old unless there are important contraindications for peritoneal dialysis. It is more difficult to establish adequate access for hemodialysis in children less than $10 \mathrm{~kg}$. Catheter of appropriate diameter (temporary access) is sometimes needed to be placed into major vessels. Dual-and single-lumen cuffed catheters are now available for even very small children (5 to $10 \mathrm{~kg}$ body weight) [4]. 
The hands of a skilled pediatric access surgeon, an arteriovenous loop graft in the thigh may be possible for patients more than $10 \mathrm{~kg}$ and a primary arteriovenous fistula in the forearm for patients more than 15 $\mathrm{kg}$ (permanent access) may be needed. In general, permanent access is extremely difficult when patients are smaller than $20 \mathrm{~kg}$. A surgeon or pediatric nephrology that is skilled in these procedures [5]. "Hemodialysis is a transient treatment for patients who are candidates for kidney transplantation and a permanent treatment for the end-stage renal disease (ESRD) patients with no chance of transplantation [6]. The quality of dialysis is reduced and its related morbidity and mortality are increased when an appropriate vascular access are used [7].The most important cause for high morbidity and mortality among hemodialysis patients is avascular access complications [8]. The success of chronic haemodialysis depends on good vascular access. The ideal vascular access should provide effective and safe therapy by enabling the removal and return of blood extracorporeal circuit. Vascular access should be reliable, easy to use and have minimal risk to the individual receiving haemodialysis [3]. Vascular access is a prerequisite for hemodialysis. That simple statement of fact understates the complexity of establishing and maintaining vascular access sufficient to provide adequate dialysis for long-term kidney replacement therapy and additionally camouflages the episodic nature of complications [9].Vascular access complications occurred in $21 \%$ to $31 \%$ of hemodialysis patients, and it increased the duration of a hospitalization stay by 9 to 13 days [10,11].The planning and creation of vascular access for hemodialysis patients is one of the most important aspects in the total management of patients with end stage renal disease (ESRD). A skillful meticulous operative procedure and careful planning are the most important determinants of the life-line for patients with ESRD [12]. Vascular access for pediatric hemodialysis is a complex procedure that requires specialized nurse's preparation. It incorporates the use of highly technical equipment. Nurses are considered to be the cause of success of the management and prevention of complications in dialysis units. Moreover, to improve the outcomes and reduce complications of hemodialysis vascular access, a multidisciplinary approach should be developed and involves nephrologists, access surgeons, radiologists and dialysis nurses[13].The ability to minimize and accurately recognize access problems requires adequate education of nurses and physicians because their experience has been documented to be the most frequently related cause of vascular access complications. The developments of standards of care and expertise in staff are important components to successfully prevent vascular access complications [14].

Vascular access assessment is the most important tasks for hemodialysis nurses and personnelwho assisting in the performance of procedure. These tasks require knowledge, professionalism and special education to be master. The hemodialysis nurse and dialysis personnel must synthesize the knowledge and education they possess in every decision regarding dialysis therapy intervention and desired treatment outcomes [15].

The hemodialysis nurses and technicians are responsible for day-to-day consistency of the vascular access care process and patient education, including: knowledgeable access assessment at each treatment; performing access surveillance; maintain vascular access; using strict aseptic technique and all dialysis precautions; documenting the assessment, interventions; reporting all abnormalities and complications to nurse manager [16].

\section{Aim of the study}

The aim of this study was to assess nurses' Knowledge and Performance about the maintenance and prevention of vascular access complications in some pediatric hemodialysis units.

\section{Research question:}

1. What are the level of nurses' Knowledge about the maintenance and prevention of vascular access complications at selected setting?

2. What are the level of nurses' Performance on the maintenance and prevention of vascular access complications at selected setting?

3. What is the relationship between nurses' knowledge and biosocial characteristics?

Research design:-

\section{Subjects And Method}

A descriptive comparative design was selected.

Settings:-

This study was conducted at pediatric hemodialysis units in Menoufia Governorate:

1- Ministry of Health Hospitals at Shebin El kom Teaching Hospital and Health Insurance Hospital for Students.

2- Menoufia University Hospitals at Shebin El kom and Mansheat Sultan. Sample:-

A convenience sample of 100 staff nurses was obtained from the selected pediatric hemodialysis units in Menoufia Governorate, Egypt. Data was collected from 48 nurses from Ministry of health hospitals. Also, data was collected from 52 nurses from Menoufia university hospitals. 
Criteria of sample selection:

The only criteria for sample selection were that all nurses should be providing direct care for children or adolescence receiving hemodialysis.

\section{Instruments for Data Collection:}

Two tools were developed by the researcher for data collection

Tool 1: Knowledge assessment questionnaire. It was designed by the investigator after reviewing related literature. It included 34 questions. This tool was divided into five parts.

Part I: Biosocial characteristics of nurses:- It included nurse's age, marital status, level of education, job title, hospital name, and years of experience in the hemodialysis unit.

Part II: Nurse's general knowledge of pediatric hemodialysis vascular access.

It contained two questions about definition of pediatric hemodialysis vascular access and its types. The total score of this part was 4 points.

Part III: Nurse's knowledge about temporary vascular access for pediatric hemodialysis.

It included 10 questions about definition of temporary vascular access, types of used veins, indications and contraindications of jugular and subclavian vein types selection, indications of selection of femoral vein, mechanical complications, signs and symptoms of mechanical complications, late complications, signs and symptoms of late complications, nursing role for the maintenance and prevention of temporary vascular access complications. The total score of this part was 20 points.

Part IV: Nurse's knowledge about permanent vascular access for pediatric hemodialysis. It included 20 questions about definition, location and time of starting permanent vascular access. Other questions were included about advantages and disadvantages of fistula and grafting, contraindications, types of needles used for fistula puncturing and grafting, places of locating needles, importance of appropriate positioning of needless, role of nurses for the maintenance and caring of permanent vascular access (fistula and graft), complications of permanent vascular access, signs and symptoms of complications, role of nurses for the prevention of permanent vascular access complications in pediatric hemodialysis patients. The total score of this part was 40 points.

Part V: Knowledge of Nurses about their roles in the maintenance of vascular access in pediatric hemodialysis patients. It included two questions about nurse's roles in follow-up and required health education for patients and their families. The total score of this part was 4 points.

\section{Scoring system for nurse's knowledge:-}

\begin{tabular}{|l|l|}
\hline Score & Level of nurses knowledge \\
\hline 2 & Complete answer \\
1 & Incomplete answer \\
0 & Wrong answer \\
\hline
\end{tabular}

Tool 2: -Observational checklist for nurses interventions in the maintenance of vascular access and prevention of its complications. It was divided into three parts:-

Part I: Observational checklist for nurse's performance in the maintenance and follow up for temporary vascular access. It included 6 statements (wash hand, prepare equipment, explain procedure, evaluate the patency of catheter, assess for signs of infections and document procedure in patient's record).

Part 2: Observational checklist for nurse's performance in the maintenance and follow up of permanent vascular access. It included 10 statements (explain procedure, prepare equipment, wash hand, observe for bleeding or hematoma, check for capillary refill, compare temperature and color of extremities. Other statements related to inquire about altered sensations distal to permanent vascular access, wash hand after performing procedure and document procedure in patient's record).

Scoring system for nurse's performance:-

\begin{tabular}{|l|l|}
\hline Score & Level of nurses performance \\
\hline 2 & Adequate \\
1 & In adequate \\
0 & Not done \\
\hline
\end{tabular}

Data collection procedure:-

- Data collection was started on the first of January and lasted until August 2012. An official letters was sent from the Dean of the faculty of Nursing, Menoufia University to the directors of the selected hospital with an explanation of the aim of the study to get their permission.

- This study was conducted 3 days per week.

- Data was collected during morning, afternoon and night shifts. Studied nurses were interviewed to assess their knowledge.

- Before interviewing nurses, the researcher introduced herself to the nursing staff and explained the purpose of research. Each nurse was individually interviewed for one hour. 
- At first, data was collected about the biosocial characteristics of nurses. Then, data was collected about knowledge of nurses about temporary and permanent vascular access as well as their nursing roles.

- Afterwards, an observation of nurse's practice was done. The researcher observed the actual nurses performance without providing any information related to the ideal nursing performance. The obtained data was documented in the developed tool.

\section{Ethical Consideration}

"Protection of nurse's rights, oral consent was obtained from the participants to share in the study, the researchers initially introduced themselves to all participants. They were informed about aim of the study and what was expected of her. Each participant was notified about the right to refuse to participate in the study, before taking her verbal consent".

\section{Tools development}

Validity: Tools were reviewed and tested for content validity by 5 pediatric nursing and medicine experts. Reliability: The internal consistency of the questionnaires was calculated using Cronbach's alpha coefficients. Test-retest was used. The Cronbach's alpha of the questionnaire was 0.86 indicate good reliability".

\section{Pilot study}

A pilot study was carried out on five nurses to assess the clarity, the time needed to fill each tool. The pilot study sample was not included in the total sample of the study. Results of the pilot study were used to confirm the extent to which the items of the questionnaire were related to each other. Meetings were conducted with nurses to establish a good relationship, to check the availability of conducting the research, to reassure that anonymity and confidentiality of responses would be respected.

\section{Statistical analysis}

Data was coded and transformed into specially designed form to be suitable for computer entry process. It was expressed in the form of mean and standard deviation (SD). Data was analyzed by using SPSS statistical package version 20.0. Data of the obtained statistical analysis was expressed in the form of numbers and percentages. One way analysis of variance (f-test) was used for comparison of the means of more than two groups of normally distributed groups. Quantitative data was followed by LSD Post-hoc test for multiple pairwise comparisons of two groups for quantitative variables. Qualitative data was expressed in the form of numbers and percentage. It was analyzed by chi-square $\left(\mathrm{X}^{2}\right)$ and Fisher exact test. Level of significance was set as P-value $<0.05$.

\section{Results}

Table (1) it shows that the mean age of nurses in Ministry of health hospitals group was $24.69+3.86$ years and the mean age of nurses in university hospitals group was $26.69+6.79$ years. The majority of nurses $(69.2 \%$ and79.1\%) in Ministry of health hospitals and university hospitals respectively had completed their university education. Also, the most $(52.1 \%)$ of nurses in Ministry of health hospitals had less than one years of experience, while $42.3 \%$ of nurses in university hospitals had $<6$ years of experience.

Table (2) Clarifies general knowledge of nurses about hemodialysis vascular access. This study represented that there were no statistical significant differences between knowledge of nurses in Ministry of health hospitals and university hospitals $(\mathrm{p}>0.05)$.

Table (3) presents nurses' knowledge about temporary vascular access. It can be seen from this table that statistical significant differences were found at 5\% and $1 \%$ between knowledge of nurses in Ministry of health hospitals and university hospitals respectively regarding veins used and contraindications of using subclavian and jugular veins.

Table (4) clarifies nurses' knowledge about permanent vascular access. It was obvious that a statistical significant difference was found between knowledge of nurses in Ministry of health hospitals and university hospitals about time of starting the utilization of fistula, definition of graft, time of starting the use of graft and advantages of graft. On the other hand, there was a highly statistical significant difference between both groups regarding sites of fistula, contraindications of fistula, sites of graft and contraindications of graft.

Table (5) Reveals nurses' knowledge about needles used to puncture fistula or graft. There was a highly statistical significant difference between nurses' knowledge in Ministry of health hospitals and university hospitals related to types of needles, points of placing needles and importance of appropriate positioning of needles $(\mathrm{p}<0.001)$.

Table (6) displays nurses' knowledge of the maintenance of vascular access. It was clear that a statistical significant difference were found between nurse's knowledge in Ministry of health hospitals and university hospitals regarding role of the nurse in continuous maintenance of vascular access and family and child health education. 
Table (7) shows total nurses knowledge about vascular access. There were statistical significant differences between total nurses' knowledge in Ministry of health hospitals and university hospitals regarding temporary vascular access, permanent vascular access, maintenance and follow up of vascular access and general knowledge about vascular access.

Figure (1) Shows that the most common type of vascular access was the permanent type fistula.

Figure (2) Shows that the most common type of temporary vascular access was the jugular vein followed by femoral vein.

Figure (3) Shows that bachelor degree nurses had the highest level of knowledge about permanent vascular access followed by nurses whose age ranged between $31>40$ years and nurses who had 6-10 years of experience.

Table (8) shows nurses' performance for the maintenance and follow- up for temporary vascular access. It was noted that no statistical significant differences were found between nurse's performance in Ministry of health hospitals and university hospitals.

Table (9) shows nurses' performance for the maintenance and follow-up of permanent vascular access. There was a highly statistical significant difference between nurses' performance in Ministry of Health hospitals and University hospitals in explaining procedure ,checking for capillary refill, comparing temperature and color of extremities, washing hands after performing procedure and documenting procedure $(\mathrm{p}<0.001)$. Meanwhile, there was a statistical significant difference between nurses' performance in both groups related to washing hands, inquiring about altered sensations distal to vascular access and searching for signs of infection $(\mathrm{p}<0.05)$.

Table (10) shows total nurses' performance regarding hemodialysis vascular access. Highly statistical significant differences were found between total nurse's performance in Ministry of Health hospitals and university hospitals regarding temporary vascular access and permanent vascular access.

Table (1): Distribution of Biosocial Characteristics of Studied Nurses

\begin{tabular}{|c|c|c|c|c|}
\hline \multirow[t]{3}{*}{ Biosocial data } & \multirow{2}{*}{\multicolumn{2}{|c|}{$\begin{array}{c}\text { Ministry of Health Hospitals } \\
(n=48)\end{array}$}} & \multirow{2}{*}{\multicolumn{2}{|c|}{$\begin{array}{c}\text { Nurses in pediatric hemodialy } \\
\text { Menoufia University Hospital } \\
(\mathrm{n}=\mathbf{5 2})\end{array}$}} \\
\hline & & & & \\
\hline & No & $\%$ & No & $\%$ \\
\hline \multirow{2}{*}{$\begin{array}{l}\text { - Age (years) } \\
0<20 \\
20-30 \\
31>40 \\
(\mathrm{X} \pm \mathrm{SD})\end{array}$} & $\begin{array}{c}0 \\
44 \\
4 \\
\end{array}$ & $\begin{array}{c}0.0 \\
91.7 \\
8.3 \\
\end{array}$ & $\begin{array}{c}8 \\
29 \\
15 \\
\end{array}$ & $\begin{array}{l}15.4 \\
55.8 \\
28.8 \\
\end{array}$ \\
\hline & \multicolumn{2}{|c|}{$24.69 \pm 3.86$} & \multicolumn{2}{|c|}{$26.69 \pm 6.79$} \\
\hline $\begin{array}{l}\text { Marital status } \\
\text { Married } \\
\text { Single }\end{array}$ & $\begin{array}{l}17 \\
31\end{array}$ & $\begin{array}{l}35.4 \\
64.4\end{array}$ & $\begin{array}{l}24 \\
28\end{array}$ & $\begin{array}{l}46.2 \\
53.8\end{array}$ \\
\hline $\begin{array}{l}\text { Educational level } \\
\text { Secondary School Diploma } \\
\text { Technical Nursing } \\
\text { Faculty of Nursing }\end{array}$ & $\begin{array}{c}16 \\
0 \\
36\end{array}$ & $\begin{array}{c}30.8 \\
0.0 \\
69.2\end{array}$ & $\begin{array}{c}7 \\
3 \\
38\end{array}$ & $\begin{array}{c}14.6 \\
6.2 \\
79.1\end{array}$ \\
\hline $\begin{array}{l}\text { Occupation } \\
\text { Nurse } \\
\text { Interns } \\
\text { Head Nurse }\end{array}$ & $\begin{array}{c}23 \\
24 \\
1\end{array}$ & $\begin{array}{c}47.9 \\
50.00 \\
2.1\end{array}$ & $\begin{array}{c}49 \\
0 \\
3\end{array}$ & $\begin{array}{c}94.2 \\
0.0 \\
5.8\end{array}$ \\
\hline $\begin{array}{l}\text { Years of experience } \\
0<1 \\
1<6 \\
6<10 \\
10>\text { more }\end{array}$ & $\begin{array}{c}25 \\
16 \\
5 \\
2\end{array}$ & $\begin{array}{c}52.1 \\
33.3 \\
10.4 \\
4.2\end{array}$ & $\begin{array}{c}13 \\
22 \\
12 \\
5\end{array}$ & $\begin{array}{c}25.0 \\
42.3 \\
23.1 \\
9.6\end{array}$ \\
\hline
\end{tabular}

Table (2): General Knowledge of Nurses about Hemodialysis Vascular Access

\begin{tabular}{|c|c|c|c|c|c|}
\hline \multirow[t]{3}{*}{ Nurses Knowledge } & \multicolumn{4}{|c|}{ Nurses in pediatric hemodialysis units } & \multirow[t]{3}{*}{$\mathbf{X}^{2}$} \\
\hline & \multicolumn{2}{|c|}{$\begin{array}{l}\text { Ministry of Health Hospitals } \\
\qquad(n=48)\end{array}$} & \multicolumn{2}{|c|}{$\begin{array}{l}\text { Menoufia University Hospitals } \\
\qquad(\mathbf{n}=\mathbf{5 2})\end{array}$} & \\
\hline & No & $\%$ & No & $\%$ & \\
\hline \multicolumn{6}{|c|}{ Definition of vascular access } \\
\hline Complete answer & 1 & 2.1 & 2 & 3.8 & $2.64^{\text {n.s }}$ \\
\hline Incomplete answer & 30 & 62.5 & 39 & 75.0 & \\
\hline Wrong answer & 17 & 35.4 & 11 & 21.2 & \\
\hline \multicolumn{6}{|c|}{$\begin{array}{l}\text { Types of vascular access for } \\
\text { pediatric hemodialysis }\end{array}$} \\
\hline Complete answer & 1 & 2.1 & 5 & 9.6 & $3.95^{\mathrm{n} . \mathrm{s}}$ \\
\hline Incomplete answer & $\begin{array}{l}33 \\
14\end{array}$ & 68.8 & 38 & 73.1 & \\
\hline Wrong answer & 14 & 29.2 & 9 & 17.3 & \\
\hline
\end{tabular}

N.B: n.s Not significante 
Table (3): Nurses Knowledge about Temporary Vascular access

\begin{tabular}{|c|c|c|c|c|c|c|c|c|c|c|c|c|c|}
\hline \multirow{3}{*}{ Nurses Knowledge } & \multicolumn{6}{|c|}{$\begin{array}{c}\text { Ministry of Health hospitals } \\
(n=48)\end{array}$} & \multicolumn{6}{|c|}{$\begin{array}{l}\text { Menoufia University Hospitals } \\
(\mathrm{n}=\mathbf{5 2})\end{array}$} & \multirow{3}{*}{$\mathbf{X}^{2}$} \\
\hline & \multicolumn{2}{|c|}{ Complete } & \multicolumn{2}{|c|}{ Incomplete } & \multicolumn{2}{|c|}{ Wrong } & \multicolumn{2}{|c|}{ Complete } & \multicolumn{2}{|c|}{ Incomplete } & \multicolumn{2}{|c|}{ Wrong } & \\
\hline & No & $\%$ & No & $\%$ & No & $\%$ & No & $\%$ & No & $\%$ & No & $\%$ & \\
\hline $\begin{array}{l}\text {-Definition of temporary } \\
\text { vascular access }\end{array}$ & 1 & 2.1 & 27 & 57.4 & 20 & 14.7 & 3 & 5.8 & 20 & 38.5 & 29 & 55.8 & $3.54^{\text {n.s }}$ \\
\hline -Veins used & 2 & 4.2 & 35 & 72.9 & 11 & 22.9 & 10 & 19.2 & 37 & 71.2 & 5 & 9.6 & $7.49^{*}$ \\
\hline $\begin{array}{l}\text {-Indications of using } \\
\text { subclavian or jugular veins }\end{array}$ & 0 & 0.0 & 14 & 29.2 & 34 & 70.8 & 1 & 1.9 & 23 & 44.2 & 28 & 53.8 & $3.62^{\text {n.s }}$ \\
\hline $\begin{array}{l}\text {-Contraindications of using } \\
\text { these veins }\end{array}$ & 0 & 0.0 & 6 & 12.5 & 42 & 87.5 & 0 & 0.0 & 25 & 48.1 & 27 & 51.9 & $14.77 * *$ \\
\hline $\begin{array}{l}\text {-Indications of using } \\
\text { femoral veins }\end{array}$ & 1 & 2.1 & 29 & 60.4 & 18 & 37.5 & 1 & 1.9 & 41 & 78.8 & 10 & 19.2 & $4.19^{\text {n.s }}$ \\
\hline -Mechanical complications & 2 & 4.2 & 22 & 45.8 & 24 & 50.0 & 0 & 0.0 & 31 & 59.6 & 21 & 40.4 & $3.57^{\text {n.s }}$ \\
\hline $\begin{array}{l}\text {-Manifestations of } \\
\text { mechanical complications }\end{array}$ & 0 & 0.0 & 23 & 47.9 & 25 & 52.1 & 0 & 0.0 & 23 & 44.2 & 29 & 55.8 & $0.14^{\text {n.s }}$ \\
\hline -Late complications & 1 & 2.1 & 22 & 45.8 & 25 & 52.1 & 0 & 0.0 & 24 & 46.2 & 28 & 53.8 & $1.10^{\text {n.s }}$ \\
\hline $\begin{array}{l}\text {-Manifestations of late } \\
\text { complications }\end{array}$ & 0 & 0.0 & 17 & 35.4 & 31 & 64.6 & 0 & 0.0 & 25 & 48.1 & 27 & 51.9 & $1.64^{\mathrm{n} . \mathrm{s}}$ \\
\hline $\begin{array}{l}\text {-Role of nurses in the } \\
\text { maintenance and } \\
\text { prevention of temporary } \\
\text { vascular access } \\
\text { complications }\end{array}$ & 0 & 0.0 & 35 & 72.9 & 13 & 27.1 & 0 & 0.0 & 34 & 65.4 & 18 & 44.6 & $0.66^{\mathrm{n} . \mathrm{s}}$ \\
\hline
\end{tabular}

N.B: * Significant

* Highly significant

n.s No significant 
Table (4): Nurses Knowledge about Permanent (Fistula and Graft) Vascular Access

\begin{tabular}{|c|c|c|c|c|c|c|c|c|c|c|c|c|c|}
\hline \multirow{3}{*}{ Nurses Knowledge } & \multicolumn{6}{|c|}{$\begin{array}{l}\text { Ministry of Health hospitals } \\
\qquad(n=48)\end{array}$} & \multicolumn{6}{|c|}{$\begin{array}{l}\text { Menoufia University Hospitals } \\
\qquad(\mathrm{n}=\mathbf{5 2})\end{array}$} & \multirow{3}{*}{$\mathbf{X}^{2}$} \\
\hline & \multicolumn{2}{|c|}{ Complete } & \multicolumn{2}{|c|}{ Incomplete } & \multicolumn{2}{|c|}{ Wrong } & \multicolumn{2}{|c|}{ Complete } & \multicolumn{2}{|c|}{ Incomplete } & \multicolumn{2}{|c|}{ Wrong } & \\
\hline & No & $\%$ & No & $\%$ & No & $\%$ & No & $\%$ & No & $\%$ & No & $\%$ & \\
\hline$\frac{\text { A. Fistula }}{\text {-Definition }}$ & 1 & 2.1 & 32 & 66.7 & 15 & 31.3 & 2 & 3.8 & 35 & 67.4 & 15 & 28.8 & $0.31^{\mathrm{n} . \mathrm{s}}$ \\
\hline -Sites of fistula & 0 & 0.0 & 22 & 45.8 & 26 & 54.2 & 4 & 7.6 & 37 & 71.2 & 11 & 12.2 & $13.76^{* *}$ \\
\hline $\begin{array}{l}\text {-Time of starting use of } \\
\text { fistula }\end{array}$ & 2 & 4.1 & 20 & 41.7 & 26 & 54.2 & 1 & 1.9 & 36 & 69.2 & 15 & 28.8 & $7.71 *$ \\
\hline -Advantages of fistula & 0 & 0.0 & 5 & 10.4 & 43 & 89.6 & 0 & 0.0 & 13 & 25.0 & 39 & 75.0 & $3.60^{\text {n.s }}$ \\
\hline $\begin{array}{l}\text {-Disadvantages of } \\
\text { fistula }\end{array}$ & 0 & 0.0 & 5 & 10.4 & 43 & 89.6 & 0 & 0.0 & 13 & 25.0 & 39 & 75.0 & $3.60^{\text {n.s }}$ \\
\hline -Contraindications & 0 & 0.0 & 3 & 6.2 & 45 & 93.8 & 1 & 1.9 & 25 & 48.1 & 26 & 50.0 & $23.25 * *$ \\
\hline $\begin{array}{l}\text {-Nursing care for } \\
\text { maintenance of fistula }\end{array}$ & 0 & 0.0 & 31 & 64.6 & 17 & 35.4 & 0 & 0.0 & 40 & 76.9 & 12 & 23.1 & $1.85^{\mathrm{n} . \mathrm{s}}$ \\
\hline$\frac{\text { B. Graft }}{\text {-Definition }}$ & 1 & 2.1 & 2 & 4.2 & 45 & 93.8 & 1 & 1.9 & 11 & 21.2 & 40 & 76.9 & $6.38^{*}$ \\
\hline -Sites of graft & 0 & 0.0 & 2 & 4.2 & 26 & .95 .8 & 0 & 0.0 & 13 & 25.0 & 39 & 75.0 & $8.50 * *$ \\
\hline $\begin{array}{l}\text {-Time of starting use of } \\
\text { graft }\end{array}$ & 0 & 0.0 & 3 & 6.2 & 45 & 93.8 & 0 & 0.0 & 13 & 25.0 & 39 & 75.0 & $6.53 *$ \\
\hline -Advantages of graft & 0 & 0.0 & 1 & 2.1 & 47 & 97.9 & 0 & 0.0 & 8 & 15.4 & 44 & 84.6 & $5.39 *$ \\
\hline -Disadvantages of graft & 0 & 0.0 & 5 & 10.4 & 43 & 89.6 & 0 & 0.0 & 13 & 25.0 & 39 & 75.0 & $3.60^{\text {n.s }}$ \\
\hline -Contraindications & 0 & 0.0 & 0 & 0.0 & 48 & 100.0 & 0 & 0.0 & 13 & 25.0 & 39 & 75.0 & $13.79 * *$ \\
\hline $\begin{array}{l}\text {-Nursing care for } \\
\text { maintenance of graft }\end{array}$ & 0 & 0.0 & 31 & 64.6 & 17 & 35.4 & 0 & 0.0 & 40 & 76.9 & 12 & 23.1 & $1.85^{\mathrm{n} . \mathrm{s}}$ \\
\hline $\begin{array}{l}\text { C. Complications of } \\
\text { permanent vascular } \\
\text { access } \\
\text {-Complications of } \\
\text { permanent vascular } \\
\text { access }\end{array}$ & 0 & 0.0 & 36 & 75.0 & 12 & 25.0 & 0 & 0.0 & 36 & 69.2 & 16 & 30.8 & $0.41^{\mathrm{n} . \mathrm{s}}$ \\
\hline $\begin{array}{l}\text {-Manifestations of } \\
\text { these complications }\end{array}$ & 0 & 0.0 & 22 & 45.8 & 26 & 54.2 & 0 & 0.0 & 31 & 59.6 & 21 & 40.4 & $1.90^{\mathrm{n} . \mathrm{s}}$ \\
\hline $\begin{array}{l}\text { Role of nurse to } \\
\text { prevent these } \\
\text { complications }\end{array}$ & 0 & 0.0 & 37 & 77.1 & 11 & 22.9 & 0 & 0.0 & 31 & 59.6 & 21 & 40.4 & $3.50^{\mathrm{n} . \mathrm{s}}$ \\
\hline
\end{tabular}

N.B: * Significant

** highly significant

n.s No significant

Table (5): Nurse's Knowledge about Needles Used to Puncture Fistula or Graft

\begin{tabular}{|c|c|c|c|c|c|}
\hline \multirow[t]{3}{*}{ Nurses Knowledge } & \multicolumn{4}{|c|}{ Nurses in pediatric hemodialysis units } & \multirow[t]{3}{*}{$\mathbf{X}^{2}$} \\
\hline & \multicolumn{2}{|c|}{$\begin{array}{c}\text { Ministry of Health hospitals } \\
(n=48)\end{array}$} & \multicolumn{2}{|c|}{$\begin{array}{l}\text { Menoufia University Hospitals } \\
(\mathrm{n}=52)\end{array}$} & \\
\hline & No & $\%$ & No & $\%$ & \\
\hline Incomplete answer & 8 & 16.7 & 34 & 65.4 & $24.32 * *$ \\
\hline Wrong answer & 40 & 83.3 & 18 & 34.6 & \\
\hline \multicolumn{6}{|l|}{ Points of placing needles } \\
\hline Incomplete answer & 9 & 18.7 & 28 & 52.8 & $13.19 * *$ \\
\hline Wrong answer & 39 & 81.3 & 24 & 46.2 & \\
\hline \multicolumn{6}{|c|}{ Importance of appropriate positioning of needles } \\
\hline Incomplete answer & 41 & 85.4 & 23 & 44.2 & $18.38 * *$ \\
\hline Wrong answer & 7 & 14.6 & 29 & 55.8 & \\
\hline
\end{tabular}

\section{N.B: ** Highly significant}


Table (6): Nurse's Knowledge for the Maintenance of Vascular Access

\begin{tabular}{|c|c|c|c|c|c|}
\hline \multirow[t]{3}{*}{ Nurses Knowledge } & \multicolumn{4}{|c|}{ Nurses in pediatric hemodialysis units } & \multirow[t]{3}{*}{$\overline{\mathbf{X}^{2}}$} \\
\hline & \multicolumn{2}{|c|}{$\begin{array}{c}\text { Ministry of Health } \\
\text { hospitals } \\
(n=48)\end{array}$} & \multicolumn{2}{|c|}{$\begin{array}{c}\text { Menoufia University } \\
\text { Hospitals } \\
(\mathbf{n}=\mathbf{5 2})\end{array}$} & \\
\hline & No & $\%$ & No & $\%$ & \\
\hline \multicolumn{6}{|c|}{ Continuous maintenance of vascular access } \\
\hline Incomplete answer & 3 & 6.2 & 13 & 25.0 & $6.53^{*}$ \\
\hline Wrong answer & 45 & 93.8 & 39 & 75.0 & \\
\hline \multicolumn{6}{|l|}{ Family and child health education } \\
\hline Incomplete answer & 5 & 10.4 & 31 & 59.6 & $26.22 * *$ \\
\hline Wrong answer & 43 & 89.6 & 21 & 40.4 & \\
\hline
\end{tabular}

\section{N.B: * Significant ** highly significant}

Table (7): Total Nurse's Knowledge about Hemodialysis Vascular Access

\begin{tabular}{|l|l|l|l|}
\hline \multirow{2}{*}{ Total Nurses Knowledge } & \multicolumn{2}{|c|}{ Hemodialysis units } & \multirow{2}{*}{ t-test } \\
\cline { 2 - 3 } & $\begin{array}{c}\text { Ministry of Health } \\
\text { hospitals } \\
(\mathbf{n = 4 8 )}\end{array}$ & $\begin{array}{c}\text { Menoufia University } \\
\text { Hospitals } \\
(\mathbf{n}=\mathbf{5 2})\end{array}$ & \\
\cline { 2 - 3 } & $\mathbf{X} \pm$ SD & $\mathbf{X} \pm$ SD & \\
\hline Total knowledge about vascular access & $3.40 \pm 0.74$ & $3.77 \pm 0.70$ & $2.99^{*}$ \\
\hline Total knowledge about temporary vascular access & $16.25 \pm 2.81$ & $17.83 \pm 3.15$ & $2.89^{* *}$ \\
\hline Total knowledge about permanent vascular access & $23.44 \pm 3.09$ & $27.31 \pm 5.02$ & $4.60^{* *}$ \\
\hline $\begin{array}{l}\text { Total knowledge about the maintenance follow-up } \\
\text { of vascular access. }\end{array}$ & $2.17 \pm 0.48$ & $2.85 \pm 0.78$ & $5.22^{* *}$ \\
\hline
\end{tabular}

\section{N.B: * Significant $* *$ Highly significant}

\section{Types of vascular access}

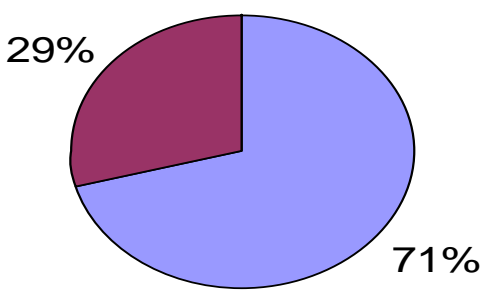

\section{1- Permanent type (fistula) $\square 2$ - Temporary}

Figure (1): Types of vascular access utilized in studied hemodialysis units

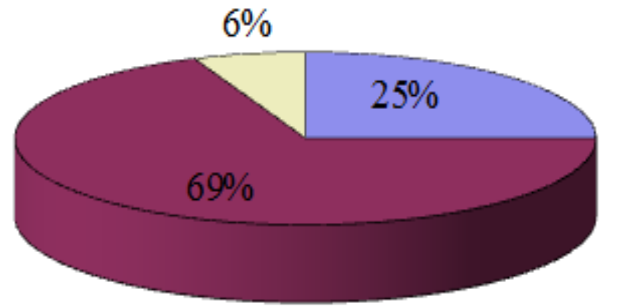

口Femoral vein

(Jugular vein (perm case

口Subclavian vein

Figure (2): Types of temporary vascular access utilized in studied hemodialysis units 


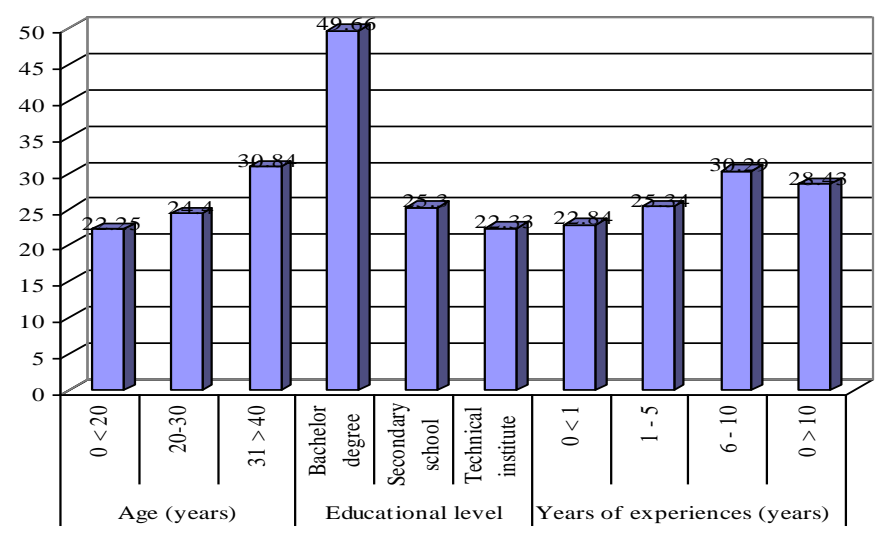

$\square$ Total nurses knowledge about permanent vascular access and their biosocial characteristic

Figure (3): Relationship between total nurse's knowledge about permanent vascular access and their biosocial characteristics

Table (8) Nurse's Performance for the Maintenance and Follow- up for Temporary Vascular Access

\begin{tabular}{|c|c|c|c|c|c|}
\hline \multirow[t]{3}{*}{ Nurses performance } & \multicolumn{4}{|c|}{ Nurses in pediatric hemodialysis units } & \multirow[t]{3}{*}{$\mathbf{X}^{2}$} \\
\hline & \multicolumn{2}{|c|}{$\begin{array}{c}\text { Ministry of Health } \\
\text { hospitals } \\
(\mathbf{n}=7)\end{array}$} & \multicolumn{2}{|c|}{$\begin{array}{c}\text { Menoufia } \\
\text { University Hospitals } \\
(\mathrm{n}=14)\end{array}$} & \\
\hline & No & $\%$ & No & $\%$ & \\
\hline \multicolumn{6}{|l|}{ Wash hands } \\
\hline Inadequate & 1 & 14.2 & 9 & 64.2 & $4.68^{\text {n.s }}$ \\
\hline Not done & 6 & 85.7 & 5 & 35.7 & \\
\hline \multicolumn{6}{|l|}{ Prepare equipment } \\
\hline Inadequate & 4 & 57.1 & 10 & 71.4 & $0.43^{\text {n.s }}$ \\
\hline Not done & 3 & 42.8 & 4 & 28.5 & \\
\hline \multicolumn{6}{|l|}{ Explain Procedure } \\
\hline Inadequate & 2 & 28.5 & 8 & 57.1 & $1.53^{\mathrm{n} . \mathrm{s}}$ \\
\hline Not Done & 5 & 28.5 & 6 & 42.8 & \\
\hline \multicolumn{6}{|c|}{ Evaluate the patency of catheter } \\
\hline Adequate & 5 & 71.4 & 8 & 57.1 & $0.040^{\text {n.s }}$ \\
\hline Not done & 2 & 28.5 & 6 & 42.8 & \\
\hline \multicolumn{6}{|l|}{ Assess for signs of infection } \\
\hline Inadequate & 6 & 85.7 & 7 & 50.0 & $1.08^{\text {n.s }}$ \\
\hline Not done & 1 & 14.2 & 7 & 50.0 & \\
\hline \multicolumn{6}{|c|}{ Document procedure in patient's record } \\
\hline Adequate & 0 & 0.0 & 4 & 28.5 & $2.47^{\text {n.s }}$ \\
\hline Inadequate & 7 & 100.0 & 10 & 71.4 & \\
\hline
\end{tabular}

N.B: n.s No significante 
Table (9) Nurse's Performance for the Maintenance and Follow-up of Permanent Vascular Access

\begin{tabular}{|c|c|c|c|c|c|}
\hline \multirow[t]{3}{*}{ Nurses performance } & \multicolumn{4}{|c|}{ Nurses in pediatric hemodialysis units } & \multirow[t]{3}{*}{$\mathbf{X}^{2}$} \\
\hline & \multicolumn{2}{|c|}{$\begin{array}{l}\text { Ministry of Health hospitals } \\
\qquad(n=41)\end{array}$} & \multicolumn{2}{|c|}{$\begin{array}{l}\text { Menoufia University Hospitals } \\
\qquad(\mathrm{n}=38)\end{array}$} & \\
\hline & No & $\%$ & No & $\%$ & \\
\hline \multicolumn{6}{|l|}{ Explain procedure } \\
\hline Inadequate & 8 & 19.5 & 28 & 73.6 & $23.33^{* *}$ \\
\hline Not done & 33 & 80.4 & 10 & 26.3 & \\
\hline \multicolumn{6}{|l|}{ Prepare equipment's } \\
\hline Inadequate & 31 & 75.6 & 34 & 89.4 & $2.6^{\text {n.s }}$ \\
\hline Not done & 10 & 24.3 & 4 & 10.5 & \\
\hline \multicolumn{6}{|l|}{ Wash hands } \\
\hline Inadequate & 9 & 18.2 & 18 & 47.3 & $5.66^{*}$ \\
\hline Not done & 32 & 78.0 & 20 & 38.5 & \\
\hline \multicolumn{6}{|c|}{ Observe for bleeding or hematoma } \\
\hline Adequate & 0 & 0.0 & 1 & 2.6 & $1.61^{\text {n.s }}$ \\
\hline Inadequate & 37 & 60.2 & 35 & 92.1 & \\
\hline Not done & 4 & 9.7 & 2 & 5.2 & \\
\hline \multicolumn{6}{|c|}{ Check for capillary refill } \\
\hline Inadequate & 5 & 12.1 & 20 & 52.6 & $14.91 * *$ \\
\hline Not done & 36 & 87.8 & 18 & 47.3 & \\
\hline \multicolumn{6}{|c|}{ Compare temperature and color of extremities } \\
\hline Adequate & 1 & 2.4 & 0 & 0.0 & $17.68^{* * *}$ \\
\hline Inadequate & 30 & 73.1 & 10 & 26.3 & \\
\hline Not done & 10 & 24.3 & 26 & 68.4 & \\
\hline \multicolumn{6}{|c|}{ Inquire about altered sensations distal to vascular access } \\
\hline Inadequate & 9 & 18.2 & 2 & 5.2 & $4.58^{*}$ \\
\hline Not done & 32 & 78.0 & 36 & 94.7 & \\
\hline \multicolumn{6}{|c|}{ Search for signs of infection } \\
\hline Adequate & 1 & 2.4 & 1 & 1.6 & $12.43 *$ \\
\hline Inadequate & 40 & 97.5 & 27 & 71.0 & \\
\hline Not done & 0 & 0.0 & 10 & 146.3 & \\
\hline \multicolumn{6}{|c|}{ Wash hands after performing procedure } \\
\hline Inadequate & 22 & 53.6 & 36 & 94.7 & $17.05^{* * *}$ \\
\hline Not done & 19 & 46.3 & 2 & 5.2 & \\
\hline \multicolumn{6}{|l|}{ Document procedure } \\
\hline Inadequate & 11 & 22.8 & 32 & 84.2 & $43.75 * *$ \\
\hline Not done & 30 & 75.6 & 6 & 15.7 & \\
\hline
\end{tabular}

N.B: * Significant

Table (10) Total nurses performance regarding hemodialysis vascular access

\begin{tabular}{|c|c|c|c|}
\hline \multirow{2}{*}{ Total Nurses performance } & \multicolumn{2}{|l|}{ Hemodialysis unites } & \multirow[b]{2}{*}{ t-test } \\
\hline & $\begin{array}{c}\text { Ministry of Health } \\
\text { hospitals } \\
\bar{x} \pm \mathrm{SD}\end{array}$ & $\begin{array}{c}\text { Menoufia University } \\
\text { Hospitals } \\
\bar{x} \pm \mathrm{SD}\end{array}$ & \\
\hline $\begin{array}{l}\text { Total nurses performance regarding temporary } \\
\text { vascular access }\end{array}$ & $47.00 \pm 5.94$ & $59.69 \pm 7.79$ & $3.75^{* *}$ \\
\hline $\begin{array}{l}\text { Total nurses performance regarding permanent } \\
\text { vascular access }\end{array}$ & $39.41 \pm 4.56$ & $47.45 \pm 3.16$ & $9.03^{* * *}$ \\
\hline
\end{tabular}

\section{N.B: * Significant $* *$ highly significant}

\section{Discussion}

Vascular access is a life line for hemodialysis patients. So that, they should receive proper nursing care in order to remain functioning well and avoid secondary complications that may happen. This study was designed to assess nurses' Knowledge and Performance about the maintenance and prevention of vascular access complications in some pediatric hemodialysis units. The present study showed that nurses in university hospitals were older than nurses in Ministry of health hospitals. It was clear that nurses with more years of experience proved to have better practice than those with have shorter experience. Current study revealed that bachelor degree nurses in Ministry of health hospitals and university hospitals had the highest level of knowledge about temporary and permanent vascular access. These results come in agreement with [17,18]who reported that nurses' education and nurses' experience was associated with fewer patient deaths. 
Regarding general nurses' knowledge about hemodialysis vascular access, there were no statistical significant differences between nurses in Ministry of health hospitals and university hospitals. Above all, in university hospitals, nurses had better knowledge about definition of vascular access and its types. This may be interpreted as there were more diploma degree nurses and no technical institute nurses at pediatric hemodialysis units in Ministry of health hospitals. Finding of the present study showed that nurses' knowledge of temporary vascular access, there were statistical significant differences between nurses' knowledge in Ministry of health hospitals and university hospitals about veins used for temporary vascular access and contraindications of using the subclavian and jugular veins. This meant that nurses in Ministry of health hospitals needed well designed training programs in temporary vascular access. This finding consistent with [19], who supported the idea that education improves the knowledge of nurses working in hemodialysis unite.

In the present study, it was foundthat there were statistical significant differences between nurse's knowledge in Ministry of health hospitals and university hospitals about sites of fistula, contraindications, time of starting use of fistula, definition of graft, sites of graft, time of starting use of graft, advantages of graft and its contraindications. This could be attributed to the nurses in university hospitals had more incomplete level of knowledge while nurses in Ministry of health hospitals had more wrong answers. Also, it was found that total nurses knowledge about permanent vascular access was higher in university hospitals than in Ministry of health hospitals. This could be due to lack of training programs in Ministry of health hospitals. Training programs help in keeping and updating nurses' knowledge as well as improving their practice [20]. Also, [21] added that hemodialysis is one of the most important areas which needed continuous updating of nurses' knowledge and skills in this context and he cited that without orientation and training, no clear outcomes could be achieved. Billings et al., (2007)[22] suggested that having on line courses is one way to simplify orientation programs that prepare nurses for clinical application. In addition, this study showed that the majority of nurses in Ministry of health hospitals and university hospitals had either incomplete or wrong knowledge about grafting. This could be due to the limited number of graft patients compared with central venous catheters and fistulas. Regarding nurses' knowledge about the maintenance of vascular access, all nurses in Ministry of health hospitals and university hospitals had either incomplete or wrong knowledge about continuous maintenance of vascular access. This could be due to their lack of knowledge about vascular access assessment, evaluation of the patency and circulation of vascular access, evaluation of signs of infection and documentation of procedure. Also, nurses in university hospitals had higher level of knowledge than nurses in Ministry of health hospitals regarding required family and child health education for the maintenance of vascular access. Above all, it was clear that all nurses in both groups had either incomplete or wrong knowledge.

This result is consistent with [23] who found that nurses did not provide health education for patients at hemodialysis about vascular access. Also, there could be other three reasons; the first reason is the shortage of specific training programs about required family and child health education for the maintenance of vascular access. The second reason could be that nurses traditionally believed that physicians are the only responsible health care personnel who provide education. American Nephrology Nurses' Association, (2013) [24] reported that patient and families should be educated on the importance of vein preservation and how to care for their vascular access. On the other hand,[25,26] reported that hemodialysis children are in intense need for psychological preparation and reassurance before any procedure. The third reason may be that nurses underestimate the importance of health education for patients. Also, this was in line with [27] who illustrated that nurses did not provide health education to patients because they had limited information concerning its importance.

Regarding nurses performance for the maintenance and follow up of temporary vascular access. The majority $(85.7 \%)$ of nurses in Ministry of health hospitals did not wash hands. The possible explanation of this result could be that nurses may be deterred by the length of time spent in hand washing and their liability for skin irritation from frequent washing. In this respect, [28] cited that Centers for Diseases Control and Prevention provided guidelines for the use of alcohol based hand rubs as an alternative for using traditional soap and water when providing care. Hand hygiene is the most important way to prevent contact transmission. Nurses should demonstrate proper hand washing technique [28]. However, these guidelines as well as facilities were not available at studied settings. Also, Most of nurses in both groups did not explain procedure, evaluate the patency of catheter, or assess for signs of infection. This could lead to serious problems such as infections and thrombosis [30].Meanwhile, all nurses in both settings were either inadequate in documentation in patient's records or did not do it at all. These findings were consistent with [25] who found that $23.3 \%$ of nurses did not achieve appropriate level of performance during and after hemodialysis procedure.

For nurses care in the maintenance and follow-up of permanent vascular access, nurses had inadequate practices in Ministry of health hospitals because more than two thirds of nurses were either inadequate or did not at all explain the procedure, prepare equipment, wash hands, observe for bleeding or hematoma, check for capillary refill, compare temperature and color of extremities, inquire about altered sensation distal to vascular access, search for signs of infection and document the procedure. This could cause many complications such as 
infection and thrombosis. Meanwhile nurses in university hospitals had a higher level of performance than nurses in Ministry of health hospitals.[28] Who found that nurses perfectly assessed access site for infections, and explain related procedure. Assessment is the key to evaluating al new and established fistulas and grafts, in order to determine patency and access readiness. Nurse's education should include principles and hands on access training to assure optimal care of the patient's access. Nurses education program should include satisfactory demonstration of knowledge and skills prior to the nurses begin allowed to independently perform access procedure [24].

\section{Conclusion}

The knowledge of studied nurses about pediatric hemodialysis vascular access was inadequate to deal with hemodialysis children. Moreover, nurses working at pediatric hemodialysis units in university hospital had better knowledge and practices related to the maintenance and follow-up of temporary vascular access, permanent vascular access.

\section{Recommendations}

In-service training education programs are needed to upgrade nurses' knowledge and practices in the maintenance and prevention of complications of temporary vascular access and permanent vascular access as well as maintenance and follow-up of vascular access.

\section{References}

[1]. Nordqvist, c. (2016). Chronic Kidney Disease. Causes, Symptoms and Treatment. Medical new today. Retrieved frohttp:// www.medicalnewstoday.com/articles/172179.php.

[2]. Kallentack, J., Gutch C., Stoner M.andCorea A. (2010). Review of Hemodialysis for Nurses and Dialysis Personnel. $7^{\text {th }}$ ed., Elsevier Mosby Inc, pp 3, $135-146,117-131$.

[3]. Kumwenda, M.(2015). Vascular Access for Hemodialysis.The Renal Association.Retrieved fromhttp:// www.renal. org/guidelines/modules/vascular -access-for-haemodialysis.

[4]. Gulati, S. and Lall, N. (2012).Hemodialysis in Children: A Simplified Approach.JIMSA . 25 (2).

[5]. Stolic,R. (2013).Most Important Chronic Complications of Arteriovenous Fistulas for Hemodialysis. Med PrincPract 2013;22:220228.

[6]. Sanford, D., Atman M., and Racheal R. (2006). Caring for our vascular access: a little effort can make a big difference. Pediatric Nephrology, 21 (4) 1-4.

[7]. National Kidney Foundation (2015). Hemodialysis access, Retrieved fromhttp://www.kidney.Org/atoz/content/hemoaccess

[8]. Gilpin V, Nichols WK. (2010). Scular access for hemodialysis: Thrills and thrombosis. J Vasc Nurs;28:78-83.

[9]. Dinwiddie, L.(2007). Overview of the Role of a Vascular Access Nurse Coordinator in the Optimization of Access Care for Patients Requiring Hemodialysis.Hong Kong J Nephrol .9 (2).(ICEER), USA.

[10]. Chhetri PK, Manandhar DN, Lamichhane S. (2009).Vascular access for hemodialysis in Nepal medical college and Teaching hospital. Nepal Med Coll J. 11:111-4.

[11]. Mohsen A, Narjes M, Negin M, and Mahmood H (2014).Factors associated with complications of vascular access site in hemodialysis patients in Isfahan Aliasghar hospital.Iran J Nurs Midwifery Res. 19(2): 208.

[12]. National Healthcare Safety Network (NHSN). (2013). Dialysis event surveillancemanual. Retrieved from http://www. cdc.gov/nhsn/dialysis/dialysis-event.html.

[13]. National Kidney and Urologic Diseases Information Clearing House. (2007).Vascular Access for Hemodialysis.from http://www.vascularaccessforhondialysis.htm.

[14]. Bresn,S.(2008).Overview of hemodialysis. Retrieved January 23fromhttp:// www.kidney.com/ ikiney/community/ pro2pro/nurses/ overview/ftemidal.

[15]. Chand, D., Brier M and Strife E., (2005). Comparison of vascular to urea clearance, anemia management, and serum albumin concentration.AMJ kidney Diseases. 45(2),303-8.

[16]. Allon, M., Lockhart M. and Billy R. (2011).Effect of preoperative sonographic mapping on vascular access outcomes in hemodialysis Patients. Kidney International,60 (2), 3013-20.

[17]. Dinwiddie, L. (2007). Overview of the Role of a Vascular Access Nurse Coordinator in the Optimization of Access Care for Patients Requiring Hemodialysis. Hong Kong J Nephrol9(2):99-103.

[18]. Tourangeau, A. (2008). Nursing skill mix and experience reduce patient mortality. Hospital Quarterly, 5(3), 19. Retrieved from http://www.longwoods.com/content/16520

[19]. Kadium, M. (2015). Improving Nurses' Knowledge to Reduce Catheter-Related Bloodstream Infection in Hemodialysis Unit. http://scholarworks.waldenu.edu/dissertations.

[20]. Gelmesz, M. and Ahcoaglu T. (2006). Effect of ingrate grated education on nurses' knowledge of hemodialysis vascular access. Pediatric Recearch, 22 (2), 87.92.

[21]. Bader, O.,(2004). Assessment of the Clinical Evaluation Process of the First Year Nursing Students.Thesis, MD.Faculty of Nursing.Alexandria University.

[22]. Billings, D., Jeffries D., Damiels D., Rawles C., Stone C. and Stephorson E. (2007). Developing and online courses to prepare nurses in staff development.Ann International, 22(2), $87-92$.

[23]. Wilson, S.E. (2009). Vascular Access: Principles and Practice. $6^{\text {th }}$ ed. Mosby company, PP 1406.

[24]. American Nephrology Nurses' Association. (2013). Vascular access for haemodialysis. Retrieved from http://www.an nurse.org/.

[25]. Hochenberry, M., Wilson D. and Winkelston M. (2009). Wong's Essentials of Pediatric Nursing. $7^{\text {th }}$, ed., Mosby Inc., PP 1001, 1004, 1008.

[26]. Mohamed, A., (2007).Assess Nursing Care Provided for Children Under Going Hemodiaylsis. UN Published Essay. Faculty of Nursing, Alexandria University. 
[27]. Ibrahim, A. (2006). Development of Patient Health Education Model to Guide Undergraduate Nursing Students.Thesis, MD, Faculty of Nursing, Alexandria University.

[28]. Kallentack, J., Gutch C., Stoner M.andCorea A. (2008). Review of Hemodialysis for Nurses and Dialysis Personnel. $7^{\text {th }}$ ed., Elsevier Mosby Inc, pp 3, $135-146,117-131$.

[29]. Grady,N.,Alexander,M., Dellinger,E., Garland,j. and Saint,s. (2011). Center for Disease Control.(CDC).Guidelines for the Prevention of Intravascular Catheter-RelatedInfections. Retrieved from http://www.cdc.gov/hicpac/

[30]. Wong's, D. (2007).Wong's nursing Care of Infants and Children. $8^{\text {th }}$ ed., Mosby Company, pp.1228-1229, $1255-1271$. 